\title{
Sensitive detection and typing of Chlamydia trachomatis using nested polymerase chain reaction
}

\author{
E H Frost, S Deslandes, D Bourgaux-Ramoisy
}

\begin{abstract}
Objectives-A method based on a nested polymerase chain reaction (PCR) was developed to detect and to type Chlamydia trachomatis from low titre samples by amplifying a large portion of the major outer membrane protein gene. The sensitivity of this procedure was evaluated in urogenital clinical samples in comparison with culture.
\end{abstract}

Specimens-A series of 787 urogenital specimens, including $37(4 \cdot 7 \%)$ positive by culture, together with 227 other samples that had been found to yield less than 25 chlamydial inclusions in culture were tested.

Methods-Samples were pelleted, resuspended in $1 \mathrm{mM} \mathrm{NaOH}$, heated and amplified without further purification. After 40 cycles of PCR, $1 \mu 1$ of product was amplified by a further 30 cycles of PCR using a second set of primers nested within the initial pair. Positives were detected by agarose gel electrophoresis and confirmed by repeating the PCR analyses and determining the serovar of both amplified samples by restriction fragment length polymorphism.

Results-Nested PCR allowed detection of $96 \%$ and culture $77 \%$ of positives with only three samples repeatedly positive by PCR but considered false positives because a different serovar was identified in the two amplifications. Of culturepositive samples with less than 11 chlamydia inclusion-forming-units $97 \%$ could be detected by nested PCR and most still gave a positive signal when diluted hundred fold.

Conclusions-Nested PCR provided the basis for a very sensitive $C$ trachomatis detection and typing strategy. Repetition and typing positive samples facilitated detection of false-positive PCR specimens resulting from contamination of the PCR process or any reagent except the original sample.

Department of Microbiology Centre hospitalier

universitaire de

Sherbrooke,

Sherbrooke, Quebec, Canada, J1H 5N4

E H Frost

E H Frost

D Bourgaux-Ramoisy

Address correspondence to: Dr E H Frost.

Accepted for publication 8 April 1993
(Genitourin Med 1993;69:290-294)

\section{Introduction}

Chlamydia trachomatis, an obligate intracellular bacterium, is probably the most common cause of urethritis, cervicitis and trachoma and, thus, optimal sensitivity and specificity in the diagnosis of this microorganism has a high priority in global health strategies. The current method of reference, culture, although highly specific, has a sensitivity of only $75-80 \%$ and requires cell culture facilities. ${ }^{1}$ Similar sensitivities are obtained for antigen detection procedures using ELISA or immunofluorescence formats. However, confirmatory or blocking tests are required to improve the specificity of antigen detection. ${ }^{2}$ The polymerase chain reaction (PCR) has recently been employed to detect the major outer membrane protein (MOMP) gene, ${ }^{3-8}$ the ribosomal RNA gene ${ }^{9}$ and a specific plasmid ${ }^{6-16}$ of $C$ trachomatis in urogenital or ocular samples. Only two of these studies, however, analysed more than 300 clinical samples $^{714}$ and none examined 100 positive specimens.

Although extremely sensitive, PCR procedures are more prone to false-positive results through contamination or "carryover" from positive specimens, in all but the most dedicated research laboratories. ${ }^{17}$ Algorithms to confirm chlamydia PCR-positive samples are, however, ill-defined. Most studies that employ ELISA ${ }^{71214}$ or immunofluorescence ${ }^{51115}$ to confirm PCR-positive, culture-negative specimens conclude that PCR is more sensitive than these other detection schemes or culture limiting their value as confirmatory tools. Only five recent studies have employed the ideal confirmatory approach which involves using a second PCR directed against a different target to confirm initial PCR results. ${ }^{69141618}$

In the present study we have employed a second PCR directed against the same target to confirm initial results.

In virtually all PCR studies, the target sequences of the positive control and all positive samples are identical, which makes it impossible to probe the origins of contamination. We, and others, have previously reported on the amplification of a large portion of the MOMP gene for typing of $C$ trachomatis isolates $^{419-21}$ and proposed that carryover could be readily identified when resulting in the generation of a series of similar serovars. These procedures ${ }^{419-21}$ lacked the sensitivity allowing detection of small numbers of chlamydial particles as maximal amplification by PCR (about $10^{9}$ fold) will not generate the $10^{10}$ DNA molecules necessary for visualization of fragments in ethidium bromidestained gels. Others have recently employed nested PCR approaches ${ }^{5822}$ or a second series of PCR with the same primers ${ }^{67}$ to amplify the single copy MOMP gene whereas the multiple-copy plasmid found in virtually all 
$C$ trachomatis isolates can be identified by a single series of PCR. ${ }^{14}$

We are presently reporting a nested PCR procedure using two pairs of primers that allow sensitive detection and typing of $C$ trachomatis. This procedure has been evaluated by screening 787 clinical samples in parallel with culture and by testing 227 known culture-positive samples with less than 25 inclusions in culture.

\section{Materials and methods}

Patients All samples received by the Microbiology Laboratory of the Centre Hospitalier Universitaire de Sherbrooke (CHUS) between 17 June, 1991 and 18 July 1991 and between 2 December, 1991 and 23 January, 1992 were analysed by culture and by PCR. In addition, samples identified as having less than 11 or from 11 to 25 inclusions in culture were accumulated and stored frozen at $-70^{\circ} \mathrm{C}$ in 1989,1990 and 1991 . The samples from men and women had been submitted in 2SP for culture of $C$ trachomatis largely from three clinics: a STD referral clinic (229 patients), a family planning clinic (317 patients) and 241 outpatients visiting the CHUS, the majority of whom were pregnant women being screened at their first prenatal visit.

Culture of $C$ trachomatis Cervical samples were taken with a Zelsmyr Cytobrush (International Cytobrush, Hollywood, Fa), urethral samples with a PN/UR (Prolabs, Richmond Hill, Ontario) cotton-tipped aluminium swab, after removing secretions when present. The swab or cytobrush tip was cut off into 2SP transport media and sent, on ice, to the laboratory where it was frozen at $-70^{\circ} \mathrm{C}$ prior to inoculation of $0.3 \mathrm{ml}$ aliquots by centrifugation at $2000 \mathrm{~g}$ for $1 \mathrm{~h}$ onto coverslips in shell vials seeded 3 days previously with McCoy cells (Ortho, Markham, Ontario). After three days in medium containing $1 \mu \mathrm{g} / \mathrm{ml}$ of cycloheximide, inclusions were revealed by immunoperoxidase staining (Ortho).

PCR sample preparation DNA was extracted from residual $2 S P$ medium by mixing with an equal volume $(0.3 \mathrm{ml})$ of $2 \mathrm{mM}$ $\mathrm{NaOH}$ and centrifuging at $14,000 \mathrm{rpm}$ for 5 $\mathrm{min}$ in a microfuge. The pellet was resuspended in $10 \mu \mathrm{l}$ of $1 \mathrm{mM} \mathrm{NaOH}$ except on rare occasions when $20-50 \mu \mathrm{l}$ of $1 \mathrm{mM}$ $\mathrm{NaOH}$ was employed because visual inspection of the pellet indicated cellular material in excess of the equivalent of $10^{5} \mathrm{McCoy}$ cells. The sample was heated at $80^{\circ} \mathrm{C}$ for $10 \mathrm{~min}$.

$P C R$ primers The first primer pair ${ }^{4}$ was: primer 1, ATGAAAAAACTCTTGAAATCGG and primer 2, GATTTTCTAGA (T,C)TTCAT(T,C)TTG with the 3' nucleotides being at positions 22 and 1048 respectively in the MOMP gene sequence of $C$ trachomatis serovar $\mathrm{L}_{2} \cdot{ }^{23}$ The second primer pair was: primer 3, GGGAATCCTGCTGAACCAAG and primer 4, AATTGCAA(G,C)GA(A,G)ACGATTTG with the 3' nucleotides being at positions 95 and 1027 respectively. ${ }^{23}$ They were synthesised on a Pharmacia Gene Assembler by the Laboratory of Molecular Biology (Faculty of Medicine, University of Sherbrooke).

$P C R$ cycling Aliquots of $5 \mu \mathrm{l}$ of sample in $50 \mu \mathrm{l}$ of PCR buffer (Amersham, Oakville, Ontario), including 1.25 units of hot tub polymerase (Amersham), $200 \mu \mathrm{M}$ dNTP (Pharmacia, Montreal, Quebec) and $1 \mu \mathrm{M}$ primers, were denatured initially for $1.5 \mathrm{~min}$ at $94^{\circ} \mathrm{C}$ and then submitted to 39 cycles of reannealing for $5 \mathrm{~min}$ at $55^{\circ} \mathrm{C}$, elongation for $3 \mathrm{~min}$ at $72^{\circ} \mathrm{C}$ and denaturation for $1 \mathrm{~min}$ at $94^{\circ} \mathrm{C}$. The final step included reannealing for $5 \mathrm{~min}$ and elongation for $10 \mathrm{~min}$. A $1 \mu \mathrm{l} \mathrm{sam-}$ ple was subjected to an analogous series of 30 cycles of PCR using the nested primer pair. Ten $\mu \mathrm{l}$ of amplified product were analysed on $1 \%$ agarose gels ( 100 volts, $2 \mathrm{~h}$ ) and stained with ethidium bromide. Positive samples were typed by restriction fragment length polymorphism analysis (RFLP) on $10 \%$ polyacrylamide gels (170 volts, $3 \mathrm{~h}$ ) as previously described ${ }^{4}$ except that the product of primers 3 and 4 rather than 1 and 2 was digested with restriction endonucleases.

$P C R$ anticontamination measures. ${ }^{17}$ Preparation and analysis of samples were performed in separate rooms using separate supplies and appliances. Plugged microtitration tips were employed for all steps prior to final sample analysis. The reaction mixture for the second PCR was assembled in the sample preparation room and the product of the first PCR amplification step added in a functioning fume hood in the sample analysis room using a micropipetter and plugged tips dedicated specifically for this purpose. All runs contained a genetically-engineered positive control (see Results) as well as negative controls. A second $5 \mu \mathrm{l}$ aliquot of the sample preparation was analysed by PCR when the first gave a positive result. Micropipetters were decontaminated weekly by a procedure devised by Dr L Delbecchi (unpublished) involving incubations in pancreatic DNase $(100 \mathrm{U} / \mathrm{ml})$ and peroxide (30 volumes) prior to rinsing in water and ethanol and final drying.

\section{Results}

When attempting to amplify $C$ trachomatis DNA from 26 samples with less than 50 inclusions in culture with a single pair of PCR primers (1 and 2), sufficient DNA for typing could only be obtained from three (12\%). A second series of PCR with primers 3 and 4 performed on a $1 \mu \mathrm{l}$ aliquot of the first amplification reaction allowed detection of 24 of these 26 samples by visualisation of an amplification product predicted from the sequence of serovar $\mathrm{L}_{2} \mathrm{MOMP}^{23}$ to be $971 \mathrm{bp}$ and thus $99 \mathrm{bp}$ shorter than that produced by primers 1 and $2 .{ }^{4}$ Other serovars should give slightly larger or smaller amplification products, ${ }^{24}$ but the differences were too small to be detected. This nested PCR procedure was employed to amplify DNA from $C$ trachomatis, from Chlamydia pneumoniae and from two 
Table Comparison of culture and nested PCR to detect $C$ trachomatis in 787 urogenital specimens

\begin{tabular}{lllc}
\hline & & $\begin{array}{l}\text { True } \\
\text { positivet }\end{array}$ & $\begin{array}{l}\text { True } \\
\text { negative }\end{array}$ \\
\hline PCR & positive* & 46 & 3 \\
Culture & negative & 2 & 736 \\
& positive & 37 & 0 \\
& negative & 11 & 739 \\
\hline
\end{tabular}

* Samples were considered PCR-positive if 2 aliquots analysed separately both gave an amplified DNA product of approximately 970 bp after nested PCR amplification.

tSamples were considered true positives if culture was positive TSamples were considered true positives if culture was positive
or if PCR was positive and analysis of the PCR-amplified or if PCR was positive and analysis of the PCR-amplified
DNA revealed the same $C$ trachomatis serovar on both amplifications.

Chlamydia psittaci samples. All 15 serovars of $C$ trachomatis could be detected but the other chlamydia species tested could only be detected if initially present in large amounts. In preliminary studies most of the false-positive samples we observed had a product identical to the positive control (an L2 serovar). This positive control was subsequently modified by digesting it with the restriction enzyme HhaI, ligating together the two fragments carrying homology to the primers and amplifying the joint fragment using primer 1 and primer 2 . The resulting product, truncated by $378 \mathrm{bp}$, was employed as a positive control.

Our original sample preparation procedure, ${ }^{4}$ employing detergents and proteinase $K$, occasionally gave negative amplification results when diluted samples were spiked with the positive control, probably because some residual protease activity survived the heat denaturation step and inactivated the DNA polymerase. A simple sample prepara-

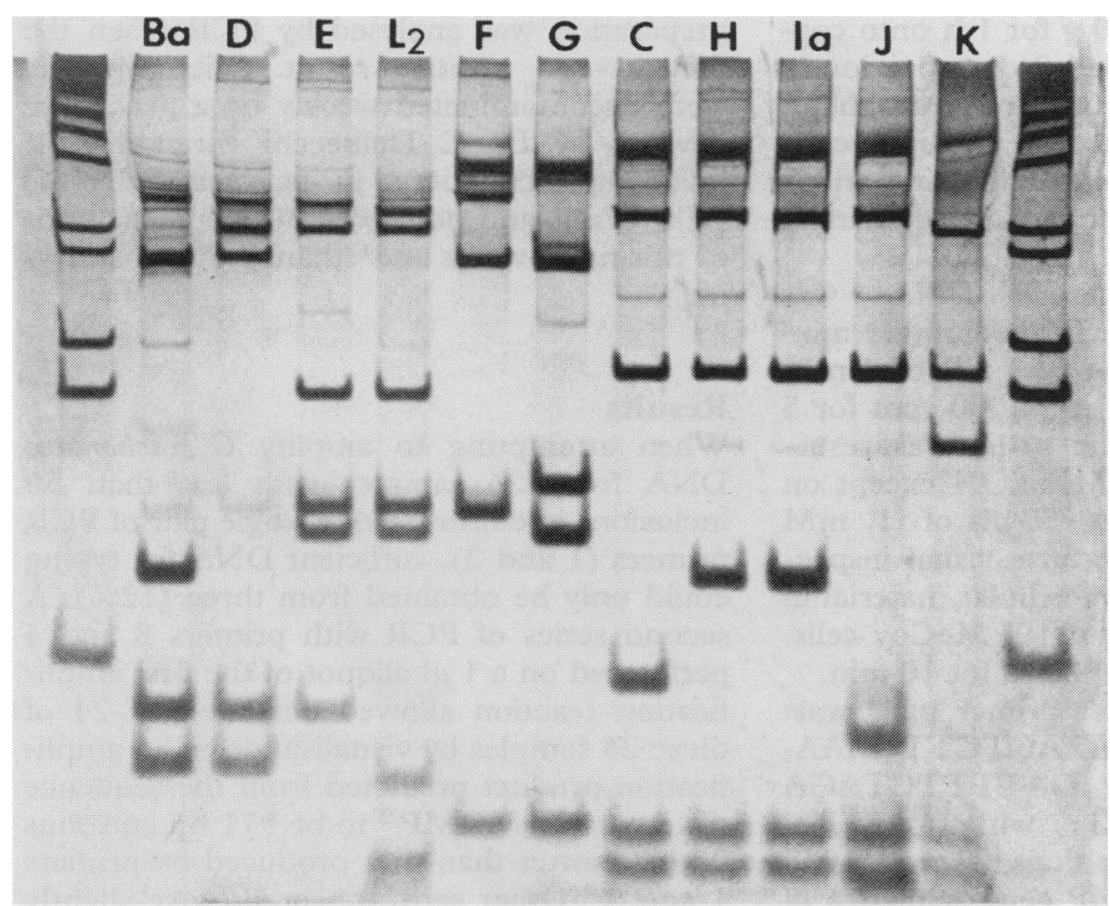

Figure AluI and MspI digestion products of nested polymerase chain reactionamplified major outer membrane protein gene from clinical samples of each of the Chlamydia trachomatis serovars (identified above the lanes) identified in this study. Fragments were separated on a $10 \%$ polyacrylamide gel and stained with silver. Serovars $H$ and $I a$ are indistinguishable in this analysis but can be differentiated when digested with restriction endonucleases Fnu4HI and HindIII. ${ }^{4} \mathrm{~A}$ molecular weight ladder is at the left and the right. tion procedure was then adopted that involved only addition of dilute alkali, pelleting chlamydia and cell debris in a microfuge, resuspending in dilute alkali and heating 10 $\min$ at $80^{\circ} \mathrm{C}$. This procedure was satisfactory for samples containing cellular materig equivalent to $10^{5} \mathrm{McCoy}$ cells as well as those with no cellular material.

This nested PCR procedure was used (sê table) to screen 787 consecutive samples that had already given unequivocal results by cu\$s ture (37 positive and 750 negative). PCR identified 49 samples that were repeatedl् positive. The chlamydial serovar was iden fied by RFLP in the amplified DNA from the 49 positives. Among the samples with positiv PCR results, only three gave a differen serovar between initial and repeat determin tions and were considered negative. The 46 specimens that could be repeated and yielded the same serovar (21 serovar E, 8 serovar Is 6 serovar F, 3 serovar $K, 2$ serovar J, 2 serovar Ia and 1 each of serovars C, G, H ang $\mathrm{L}_{2}$ - see fig) were considered true positives för $C$ trachomatis and included 35 of the 37 cuid ture-positives, the remaining two culturepositive specimens having given negative results on the initial PCR screening (but dis reveal $C$ trachomatis DNA when a secon aliquot was analysed-1 $\mathrm{E}$ and $1 \mathrm{D}$ serovart. Thus, of the 48 specimens deemed positive for $C$ trachomatis, PCR detected 46 (96\% and culture 37 (77\%). PCR identified ì positive three specimens which were sul sequently considered negative as they hae divergent serovars and culture was negatike indicating a specificity of $736 / 739$ or $99.6 \%$ (table).

In order to refine further the limit of sensi tivity of this PCR procedure, 227 samples with less than 25 inclusions in culture, including 141 with 10 or fewer inclusion were examined. $C$ trachomatis DNA was amplified from 221 (97.4\%) specimen including $137(97 \cdot 2 \%)$ of those with less tham 11 inclusions. This sensitivity is similar to that observed with the consecutive specimer even though most (23/37) of the latter hat more than 25 inclusions in culture, includin the two samples negative by PCR. The sensest tivity of nested PCR was further defined by diluting specimens with 10 or fewer inclue sions in culture. After 100-fold dilution, 19 \& 20 samples were positive. Of interest, mixed infections were detected in three of the sant ples with less than 11 inclusions.

Prior to the use of pipette tips with a corn ton plug to prepare and analyse samples, a episode of contamination was observed thô highlighted the usefulness of typing. In series of 72 samples, five of which were posf tive in culture, 24 were found to contam chlamydial DNA by PCR. Typing the amp fied DNA revealed a $K$ serovar in 18 of the 19 culture-negative, PCR-positive, specimens in this series of specimens. After decontamination of the micropipetters and subsequent use of pipette tips with cotton plugs, no further episodes of multiple samples positive for a rare serovar were observed. 


\section{Discussion}

The nested PCR procedure described in this report provided a sensitive and specific means for the detection of $C$ trachomatis in urogenital specimens as attested by analysis of over 1000 clinical specimens including 264 positive by culture. It has been shown that most discrepant results between culture and ELISA or direct immunofluorescence involved samples with few inclusions in culture. ${ }^{25}$ The sensitivity of this procedure was thus evaluated on samples yielding 25 or fewer inclusions in culture and indeed included 141 samples that produced 10 or fewer inclusions in culture and still found a sensitivity of $97 \cdot 2 \%$. As similar levels of sensitivity were observed in samples with few or many inclusions, it could be presumed that there were still abundant, detectable DNA molecules in samples with 10 or fewer inclusions in culture and that the limit of sensitivity of this PCR procedure could be ascribed to inhibitory substances in the sample rather than to paucity of DNA molecules. Indeed, even after 100 -fold dilution, we found that most samples with 10 or fewer inclusions in culture were still positive by nested PCR. This sensitivity allowed detection of $C$ trachomatis in samples negative by culture and permitted an approximation of the sensitivity of our culture system at $77 \%$. Other authors have reported similar limits for culture. ${ }^{1}$ Blind passage would probably have improved the sensitivity of our culture procedure. ${ }^{26}$

The nested PCR procedure reported here is the first method that allowed determination of all $C$ trachomatis serovars in culture-negative or weakly positive specimens. PCR protocols that amplify single-copy MOMP gene sequences with a single series of PCR have been shown to lack the sensitivity necessary to detect small numbers of chlamydial organisms ${ }^{4-719-22}$ and thus could not be used to differentiate $C$ trachomatis serovars in weakly positive or culture-negative specimens by either RFLP ${ }^{419-22}$ or direct DNA sequencing. ${ }^{27}{ }^{28} \mathrm{~A}$ very recent report used nested-PCR to distinguish trachoma serovars of $C$ trachomatis by amplification with serovar-specific primers and direct DNA sequencing. ${ }^{8} C$ psittaci strains have also been characterised by nested-PCR. ${ }^{22}$

It is now well-recognised that antigendetection methods, such as ELISA, require confirmation. $^{2}$ Ideally this confirmation involves repeating initial positives and then testing them for a different antigen or employing a blocking procedure. Only very recently have approaches to PCR confirmation based on a second PCR directed towards a different target been evaluated, ${ }^{6} 9141618$ previous studies having occasionally confirmed PCR with less-sensitive DFA or EIA procedures $^{711121415}$ or simply not attempted to validate PCR-positives. ${ }^{351013}$ Our nested PCR technique would be an ideal second assay to confirm samples deemed positive for $C$ trachomatis by PCR directed towards a different target. Indeed, the plasmid detection format, which requires only a single PCR step, would be a rapid, less-expensive, screening step. The nested PCR procedure described here, although more costly because it requires two steps of PCR, could confirm plasmid-positive samples because of its excellent sensitivity towards a different target and simultaneously provide useful additional information from positive specimens.

In most PCR applications all positive samples as well as the positive control have exactly the same sequence making it impossible to distinguish contaminated from true-positive samples. Determination of serovar permitted recognition of contamination in our initial screening by PCR. This ability to identify false-positives and trace their origin indicated that repeating initial positives (as is regularly performed in ELISA) and using a positive control that is different from the target DNA will greatly reduce, although not entirely eliminate, false positives. The number of false positives could be further reduced by typing amplified DNA and accepting as positive only those specimens yielding the same serovar on repeat PCR amplifications. Although this approach would not reveal contamination of the original sample, it would identify contamination of any of the other reagents or manipulations involved in nested PCR.

The ability to type $C$ trachomatis is a valuable tool, not only for epidemiological studies but also for confirmation of positive results obtained by virtually any other method. Although the procedure for RFLP typing outlined here is relatively simple and does not require radioisotopes, it might prove even simpler for a clinical laboratory to confirm and type with non-radioactive probes directed at individual $C$ trachomatis serovars.

We thank Dr P Bourgaux for support, discussion and critical reading of the manuscript, $\mathrm{Dr} L$ Delbecchi for sharing his micropipetter decontamination strategy with us, and Carole Picard and Ann McGee for excellent secretarial assistance.

This work was supported by Fonds FCAR grant 90 AS 2736 .

1 Schachter J. Rapid diagnosis of sexually transmitted diseases-speed has a price. Diagn Microbiol Infect Dis 1986;4:185-9.

2 Moncada J, Schachter J, Bolan G, et al. Confirmatory assay increases specificity of the chlamydiazyme test for Chlamydia trachomatis infection of the cervix. $₹$ Clin Microbiol 1990;28:1770-3.

3 Bobo L, Coutlee F, Yolken RH, Quinn T, Viscidi RP Diagnosis of Chlamydia trachomatis cervical infection by detection of amplified DNA with an enzyme immunoassay. $\mathcal{F}$ Clin Microbiol 1990;28:1968-73.

4 Frost EH, Deslandes S, Veilleux S, Bourgaux-Ramoisy D. Typing Chlamydia trachomatis by detection of restriction fragment length polymorphism in the gene encoding the major outer membrane protein. F Infect Dis 1991;163 1103-7.

5 Palmer HM, Gilroy CB, Thomas BJ, Hay PE, Gilchrist C, Taylor-Robinson D. Detection of Chlamydia trachomatis by the polymerase chain reaction in swabs and urine by the polymerase chain reaction in swabs and urine from men with

6 Ossewaarde JM, Rieffe M, Rozenberg-Arska M Ossenkoppele PM, Nawrocki RP, van Loon AM Development and clinical evaluation of a polymerase chain reaction test for detection of Chlamydia trachomatis. F Clin Microbiol 1992;30:2122-8.

7 Wu C-H, Lee M-F, Yin S-C, Yang D-M, Cheng S-F Comparison of polymerase chain reaction, monoclonal antibody based enzyme immunoassay, and cell culture for detection of Chlamydia trachomatis in genital specimens. Sex Transm Dis 1992;19:193-7.

8 Hayes LJ, Bailey RL, Mabey DCW, et al. Genotyping of Chlamydia trachomatis from a trachoma-endemic village 
in the Gambia by a nested, polymerase chain reaction: identification of strain variants. F Infect Dis 1992; 166:1173-7.

9 Claas HCJ, Wagenvoort JHT, Niesters HGM, Tio TT, van Rijsoort-Vos JH, Quint WGV. Diagnostic value of the polymerase chain reaction for chlamydia detection as determined in a follow-up study. $f$ Clin Microbio 1991;9:42-5.

10 Griffais R, Thibon M. Detection of Chlamydia trachomatis by the polymerase chain reaction. Res Microbiol 1989; 140:139-41.

11 Ostergaard L, Birkelund S, Christiansen G. Use of polymerase chain reaction for detection of Chlamydia tramerase chain reaction for detection of C
chomatis. $₹$ Clin Microbiol 1990;28:1254-60.

12 Ratti G, Moroni A, Cevenini R. Detection of Chlamydia trachomatis DNA in patients with non-gonococcal urethritis using the polymerase chain reaction. F Clin Pathol 1991;44:564-8.

13 Näher $H$, Drzonek $H$, Wolf J, von Knebel Doeberitz $M$, Petzoldt D. Detection of $C$. trachomatis in urogenital specimens by polymerase chain reaction. Genitourin Med 1991;67:211-4.

14 Mahony JB, Luinstra KE, Sellors JW, Jang D, Chernesky MA. Confirmatory polymerase chain reaction testing for Chlamydia trachomatis in first-void urine from asymptomatic and symptomatic men. F Clin Microbiol 1992; 30:2241-5.

15 Lucotte G, Petit M-C, François M-H, Réveilleau S. Detection of Chlamydia trachomatis by use of polymerase chain reaction. Mol Cell Probes 1992;6:89-92.

16 Mahony JB, Luinstra KE, Jang D, Sellors J, Chernesky MA. Chlamydia trachomatis confirmatory testing of PCR-positive genitourinary specimens using a second set of plasmid primers. Mol Cell Probes 1992;6:381-8.

17 Kwok S, Higuchi R. Avoiding false positives with PCR Nature 1989;339:237-8.

18 Holland SM, Hudson AP, Bobo L, et al. Demonstration of chlamydial RNA and DNA during a culture-negative state. Infect Immun 1992;60:2040-7.

19 Rodriguez P, Vekris A, de Barbeyrac B, Dutilh B, Bonnet
J, Bebear C. Typing of Chlamydia trachomatis by restriction endonuclease analysis of the amplified major outer membrane protein gene. f Clin Microbiol 1991;29: 1132-6.

20 Sayada C, Denamur E, Orfila J, Catalan F, Elion J. Rapid genotyping of the Chlamydia trachomatis major outer membrane protein by the polymerase chain reaction FEMS Microbiol Lett 1991;67:73-8.

21 Gaydos CA, Bobo L, Welsh L, Hook EW, Viscidi R Quinn TC. Gene typing of Chlamydia trachomatis by polymerase chain reaction and restriction endonuclease digestion. Sex Transm Dis 1992;19:303-8.

22 Kaltenboeck B, Kousoulas KG, Storz J. Two-step polymerase chain reactions and restriction endonuclease merase chain reactions and restriction endonuclease analyses detect and differentiate ompA DNA

23 Stephens RS, Mullenbach G, Sanchez-Pescador R Agabian N. Sequence analysis of the major outer membrane protein gene from Chlamydia trachomatis serova $L_{2}$. F Bacteriol 1986;168:1277-82.

24 Yuan Y, Zhang Y-X, Watkins NG, Caldwell HD Nucleotide and deduced amino acid sequences for the four variable domains of the major outer membrane proteins of the 15 Chlamydia trachomatis serovars. Infect Immun 1989;57:1040-9.

25 Hipp SS, Han Y, Murphy D. Assessment of enzyme immunoassay and immunofluorescence tests for detection of Chlamydia trachomatis. $¥$ Clin Microbiol 1987; 25:1938-43.

26 Schachter J, Martin DH. Failure of multiple passages to increase chlamydial recovery. $\mathcal{F}$ Clin Microbiol 1987;25: 1851-3.

27 Dean D, Patton M, Stephens RS. Direct sequence evaluation of the major outer membrane protein gene varian regions of Chlamydia trachomatis subtypes D', I', and $\mathrm{L}_{2}$. Infect Immun 1991;59:1579-82.

28 Poole E, Lamont I. Chlamydia trachomatis serovar differentiation by direct sequence analysis of the variable segment 4 region of the major outer membrane protein gene. Infect Immun 1992;60:1089-94. 